\title{
American International College Library Building
}

Mrs. Hobbie is librarian, American International College, Springfield, Mass.

\begin{abstract}
A merican International College is 1 a coeducational, liberal arts, nonresidential college located near the center of Springfield. There are two small dormitories on the campus, one for women the other for men, but the majority of the students come from Springfield and surrounding communities and live at home.

Unlike most colleges with building programs, money for the library at American International College came from income,
\end{abstract} not from gifts or from a special donor.

These two facts were very important factors in influencing the plans for and the construction of the college library. It was essential to build economically and to plan to accommodate at one time as large a number of the student body as possible.

The original plans for the building called for a central unit and two wings. Construction of the central unit and the right wing was completed in 1949.

The exterior of the building is brick, and the interior is cinder block, plastered in some rooms but simply painted in others. The stack areas have walls of ceramic tile. Because steel was scarce and very expensive there is very little of it in the building. The floors are reinforced poured concrete, supported by columns. During the construction of the building, the students were much interested in watching the workmen erect the columns and pour all the floor slabs before any exterior walls were begun.
In fact no walls, exterior or interior, in the building are supporting walls. This is a much less expensive type of construction than the usual steel, and this was an important item with us. Then too, it makes it possible for us to change the position of partitions in the future, if we ever decide we need to.

There are some things about the building which we like very much. By an extensive use of glass in doors and some partitions, for easy and quick supervision, it is possible in all but the busiest times, for one member of the staff to handle the main, or control desk, in the lobby.

The book collection is on open shelves and easily accessible to the students, who are encouraged to help themselves. The public catalog is in the lobby, near enough to the desk so that the students can secure help if they need to.

Back of the control desk are the reserved books, the only part of the collection on closed shelves. The faculty are very cooperative and most of them keep the number of books on reserve to a minimum. They prefer to have their students use the entire book collection whenever possible.

Opening off the lobby is the largest of three reading rooms. We shelve the current periodicals at one end of this room.

There are two other reading rooms. The building is on three levels, and on each of these levels is a reading room adjacent to, and readily accessible to the stacks, which are on each floor. In addition there are carrels in the stack areas. We have tried 
to keep our readers as near our books as possible, and to make it possible for them to secure the materials needed with the least effort.

The ceilings in the stacks areas, lobby, and offices are seven and a half feet high. In the reading room on the main floor, the ceiling is fifteen feet because the room is large and needs height. Some of our faculty and students were skeptical about the low ceilings in the lobby and other areas, but when the lights were installed and the decorating completed, they decided they liked the informal, friendly feeling which you find when you come into the building.

With our asphalt tile floors, metal shelving, ceramic tile walls in the stack areas and plenty of outlets for using electrical equipment, such as floor scrubbers, polishers and vacuum cleaners, the building is easy to keep clean at a minimum of expense.

Now what are some of the things we do not like about our building-for no building however carefully planned, is ever perfect. Many of our defects can be charged up to the need for economy. For instance, original plans called for acoustically treated ceilings throughout the building. We saved a considerable amount by finally limiting our sound absorbing ceilings to the main reading room on the first floor, our music and typing room on the second floor and the office of the librarian.

If we were building again, we would most certainly soundproof the lobby and the stack area on the first floor. In fact, we expect to do the lobby as soon as funds are available.

If we were building again we would want to change the outside entrance. The library is near the street. There is a very modest arrangement of four or five steps going to the doors-but these steps are the favorite gathering place of students with a little free time. Most of the time there are as many as fifteen or twenty gathered there, rain or shine, and their "bull" sessions get more than noisy. Since the lobby is less than fifteen feet away, it creates a real problem.

When you do not have central heating on your campus, and we do not, a boiler room becomes a problem. Unless it is completely and thoroughly insulated, the area above may suffer from over-heated floors. I speak very feelingly about this, because my office is directly over the boiler room. I suffered through the first few months, but now the ceiling of the boiler room is well insulated and my office is more comfortable.

One of our great "lacks," which will be remedied when we build the left wing is enough conference rooms. With so many of our students living off campus so that dormitory rooms are not available to them, they do need places where they can work in groups. The only room is in great demand and many students who would like to use it do not have an opportunity.

Another problem which needs some study, is the question of floors. This is not a problem at the A.I.C. library alone, for it affects other types of buildings too. When asphalt tile is laid directly on poured concrete it makes a good looking, easily maintained floor, perfectly satisfactory for the casual user. However, it may prove very tiring for the person who walks on it all day long.

Any kind of padding is expensive and the floor does not stand up when heavy furniture is placed on it. The same seems to hold true of the softer cork and other coverings.

Of course the library staff can wear especially cushioned shoes, but that is not always convenient.

Another false economy was the elimination of automatic window openers. This was a mistake for we find it difficult to

(Continued on page I73) 
again if the student loses his copy.

The librarian does not spoon-feed students. For example, if he finds a likely title in the card catalog under a subject heading not yet explored by the student, he will refer him to the subject heading rather than to the book itself. Or he will simply recommend a certain bibliography even though he has already gone through it and found several pertinent titles. At their next conference he may ask the student how productive this subject heading or that bibliography has proved to be.

In almost every instance the librarian has to decide whether to present the student with a general lead in the direction of a reference, a specific title complete with the call number, or even a text itself. The library competence of the student and the nature of the reference determine what the librarian will do. If he has encountered a pamphlet or a government document purely by chance, it is usually best to refer it to the student as specifically as possible at the same time pointing out where similar reference might be found.

A number of departments of the college, principally in the social sciences, have asked the reference librarian to address their honors students before they begin work on their theses. Here the reference librarian has the opportunity to call attention to items generally useful in their subject field and also to invite the students to confer with him individually. Reports of the reference program have spread among students and faculty with the result that students consult the reference librarian on their own initiative and more and more faculty members are asking the reference librarian to address their students.

The effects of this collaboration between student and librarian can be found in several areas of the library. More United States government documents have been used and a few students have learned to ask for them by serial document volume number. Bibliographic aids of all kinds have been given greater use. Finally the number of students who received continuing reference assistance almost doubled between the first and this second year of this program's operation. The library is an integral part of instruction.

\section{American International College Library Building}

\section{(Continued from page 148)}

regulate the windows in the main and lower level reading rooms and in the lower level stack area.

Another thing that bothers is the type of cinder block which we used. They are very porous and we discovered that sound carries through them. In many instances this is not important, but in some cases we found it necessary to insulate and plaster some walls which we had not intended to do. 'There are other quality cinder blocks available, but again, in order to economize we were forced to use a cheap grade.
Looking at the library as objectively as possible for one who is using it every day, we do feel that the good points outweigh enormously the things that irritate.

We like the good lighting, our adequate elevator, the feeling of space, the relation of one work area to another, the pleasing color, the lack of waste space in corridors and stairwells, and the attractive furnishings and equipment. As one student remarked a short time ago, "I just love to come in here and sit even when I don't have to study. It's great to think it is ours." 